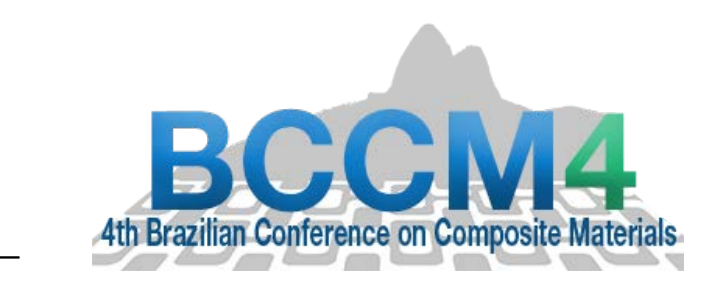

\title{
DYNAMIC ANALYSIS OF COMPOSITE STRUCTURES USING KRIGING MODEL APPLIED TO MANUFACTURING DESIGN TOLERANCES
}

\author{
Luiz Fernando Dos Santos Souza ${ }^{(1)}$, Volnei Tita ${ }^{(2)}$ and $\underline{\text { Ricardo De Medeiros }}^{(1)}$ \\ (1) Department of Mechanical Engineering, Santa Catarina State University - UDESC, Brazil \\ (2) Department of Aeronautical Engineering, São Carlos School of Engineering, University of São \\ Paulo - EESC/USP, Brazil
}

https://doi.org/10.21452/bccm4.2018.16.06

\begin{abstract}
Dynamic model updating is an effective means of damage identification, and surrogate modeling has attracted considerable attention for saving computational cost in finite element (FE) model updating, especially for large-scale structures. On the other hand, composite materials are very complex in terms of manufacturing and testing. Due to the manufacturing process, the properties of a component are very hard to control. As many damage detection methods are based on the comparison of intact and damaged plates, the definition of the intact plate must be clearly defined. This paper shows a methodology to define a frequency range to characterize a composite plate as intact structure. Using a model update process, with Kriging metamodel based on natural frequencies, the updated variables allowed to obtain the Frequency Response Function (FRF) by Finite Element Method (FEM). A set of five plates with a stacking sequence of [0/15/-15/0/15/15]s were analyzed. The applicability of the methodology is presented using one of the known plates. The presented analysis shows that it is possible to make a preliminary study to improve the manufacturing design tolerances.
\end{abstract}

\section{INTRODUCTION}

Composite materials are becoming widely applied in the industry. Many times, as an alternative, to save weight on structural components. Employing this new kind of materials, it is necessary to develop new methodologies for maintenance. On the other hand, the study of structural dynamic behavior can give enough information to evaluate components and better planning the maintenance interventions [1-3]. On the way of combining the analysis of structural behavior with strategies to monitor the structure, several Structural Health Monitoring (SHM) systems are becoming in 
evidence [4-5]. Dynamic analyses have shown high potential to evaluate damage on structures [67]. Different methods have been already presented in the literature using natural frequencies and FRFs to detect damages on composite structures [8-9]. Several damage detection methods assume that damages cause changes in the mass and stiffness matrix [10]. However, to make this assumption, it is necessary to have a good definition of the undamaged state of the component. A usual methodology is to proceed nondestructive testing on all the components, just before and after the manufacturing process in order to verify its state [11]. This is required because it is well known that the characteristics of a composite component are not easy to control. The manufacturing process has several variables that can affect the final properties of the component. Therefore, depending on the manufacturing process and the design tolerances for the structure, it is possible to define a method to provide information about the acceptability of the components based on a set of specimens, reducing the time and cost of the non-destructive evaluations.

Thus, in this work, the dynamic behavior of composite plates is evaluated in order to propose a methodology to allow a preliminary study about the acceptability of the intact state of a component. This is made based on the assessment of the structural dynamic behavior of a set of composite plates. To support this study, a numerical model is updated using a Kriging based methodology. Therefore, numerical and experimental results are used to compose a range of possibilities for the FRF that can be used to verify the state of other composite plates.

\section{METHODOLOGY}

The methodology consists of a hybrid approach using experimental and numerical data. First, a set of manufactured plates are analyzed, using modal analysis in order to get the natural frequencies and the damping factors. A range of natural frequencies is established based on the experimental data to represent a set of specimens. These experimental data are used as a reference to carry out a model update process, aiming to obtain the design variables that better represent the experimental data. Finally, using the updated design variables it is possible to obtain the FRF, which represents the entire set of composite plates. Therefore, these FRFs can be used to rank new specimens that have been manufactured with the same characteristics. In this work, a set of plates with a stacking sequence of $[0 / 15 /-15 / 0 / 15 /-15]_{s}$ is evaluated. The FRFs were obtained using lightweight structure accelerometers (Bruel \& Kjaer model 352A24), the sensitivity of 102.34 $\mathrm{mV} / \mathrm{g}$, attached to the plates. An impact hammer PCB Model 0860C3 (Piezotronics) was used to apply the impulse signal, providing the required excitation on a wide frequency spectrum. The experimental set-up used in the experiments consists of a plate hanged by elastomer wires to simulate free-free boundary conditions. Accelerometer and the impact hammer are connected to an LMS SCADAS Mobile equipment controlled by the Test.Lab software (LMS Test.Lab). Figure 1 shows the complete setup used.

Evaluating the experimental data and defining the frequency range, the model update is applied to obtain the design variables. Thus, a strategy using metamodel Kriging is implemented aiming to reduce the computational time consuming of the model update process. This strategy consists of using few numbers of FEM (Finite Element Method) simulations to train the metamodel. After that, it uses only the metamodel in the optimization process, which is required to update the model. A detailed methodology used can be found in [12]. 


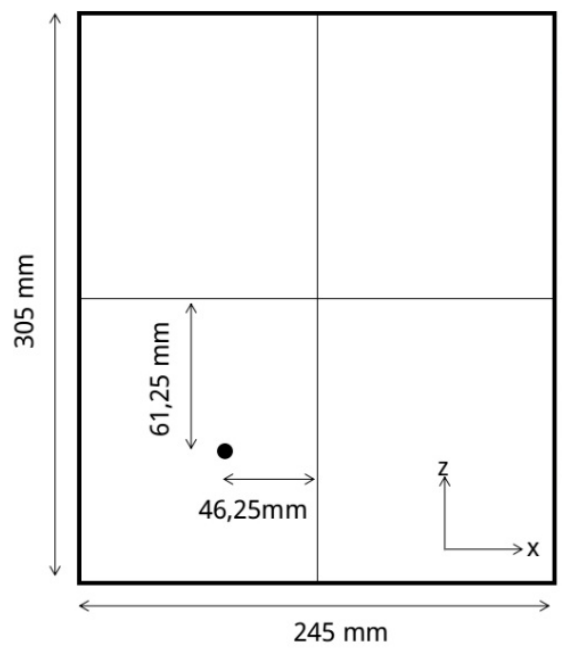

(a)

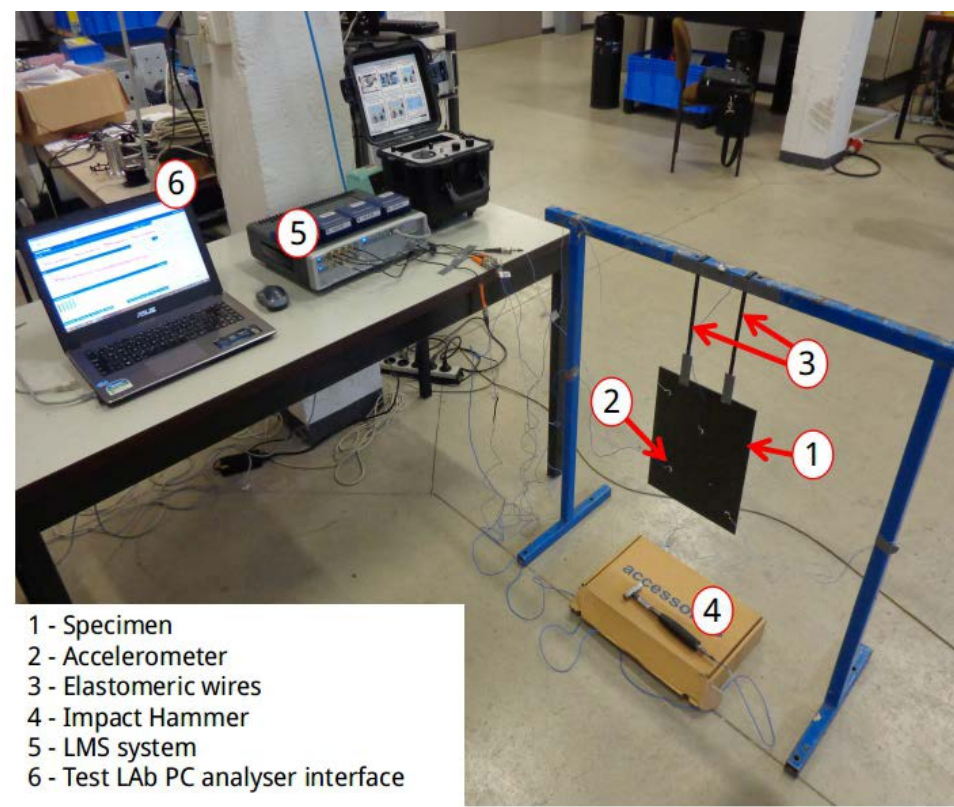

(b)

Figure 1: (a) Schematic representation of the plate and accelerometer position and (b)

Experimental setup.

Achieved the updated design variables, the FEM simulation is used to obtain the FRF of the structure. The dynamic structure response is used to define the range of the intact plates. Finally, this range can aid engineers to detect out of tolerance structures and as a reference for the manufacturing process.

\section{EXPERIMENTAL INPUT DATA}

The intact plates have been submitted to modal analysis, and the natural frequencies were obtained. Table 1 presents the experimental results for the plates [0/15/-15/0/15/-15]s, including the natural frequencies, the average, and the standard deviation.

Table 1: Experimental natural frequencies obtained experimentally for composite plates with stacking sequence $[0 / 15 /-15 / 0 / 15 /-15]_{s}$.

\begin{tabular}{lrrrrrr}
\hline & \multicolumn{1}{c}{$f_{1}[\mathrm{~Hz}]$} & $f_{2}[\mathrm{~Hz}]$ & \multicolumn{1}{c}{$f_{3}[\mathrm{~Hz}]$} & \multicolumn{1}{c}{$f_{4}[\mathrm{~Hz}]$} & $f_{5}[\mathrm{~Hz}]$ & $f_{6}[\mathrm{~Hz}]$ \\
\hline P09 & 95.379 & 132.911 & 250.645 & 316.229 & 349.436 & 405.460 \\
P10 & 104.152 & 139.884 & 261.091 & 320.690 & 367.079 & 411.455 \\
P11 & 106.412 & 144.506 & 265.334 & 332.630 & 377.859 & 424.862 \\
P12 & 107.616 & 146.244 & 268.219 & 332.774 & 381.241 & 426.971 \\
P13 & 102.961 & 139.202 & 258.850 & 320.595 & 365.101 & 412.746 \\
P14 & 99.628 & 136.840 & 258.484 & 324.150 & 361.405 & 414.755 \\
\hline Average & 103.557 & 139.543 & 259.971 & 322.420 & 366.090 & 413.751 \\
St. Dev & 4.542 & 4.902 & 6.119 & 6.824 & 11.525 & 8.280 \\
\hline
\end{tabular}


Furthermore, Table 2 presents the minimum and maximum values for each mode. Those values were obtained using the experimental average and the standard deviation, which was chosen to exemplify the problem.

Table 2: Minimum and maximum natural frequencies to characterizes the composite plates with stacking sequence $[0 / 15 /-15 / 0 / 15 /-15]_{s}$.

\begin{tabular}{lllllll}
\hline \multicolumn{7}{c}{ Boundaries fo 1 standard deviation } \\
\hline & $f_{1}[\mathrm{~Hz}]$ & $f_{2}[\mathrm{~Hz}]$ & $f_{3}[\mathrm{~Hz}]$ & $f_{4}[\mathrm{~Hz}]$ & $f_{5}[\mathrm{~Hz}]$ & $f_{6}[\mathrm{~Hz}]$ \\
\hline Min & 99.014 & 134.641 & 253.852 & 315.596 & 354.565 & 405.471 \\
Max & 108.099 & 144.445 & 266.089 & 329.244 & 377.615 & 422.030 \\
\hline
\end{tabular}

\section{NUMERICAL MODEL}

Finite element models of the laminated composite plates are used to train the Kriging model, and also to obtain the FRF curves. Abaqus ${ }^{\mathrm{TM}}$ software and Python subroutines were used to build the computational models. Based on previous studies [13], quadrilateral 8-node shell elements are used (defined as S8R5 - Abaqus nomenclature). In addition, 5640 elements and 8784 nodes are used to mesh the plate domain. This mesh size $(3 \mathrm{~mm})$ is defined after a refinement analysis to obtain the six first modes, considering the Nyquist theorem.

The numerical analyses are done considering quasi-free-free boundary conditions. In fact, the elastic wires have a very low stiffness $(10 \mathrm{~N} / \mathrm{m})$. with fixed translation $\left(U_{x}, U_{y}, U_{z}\right)$ and rotations $\left(U_{r x}, U_{r y}, U_{r z}\right)$ in the extremities non-attached to the plates. The excitation force is applied in the same position as in the experimental tests (Figure 2).

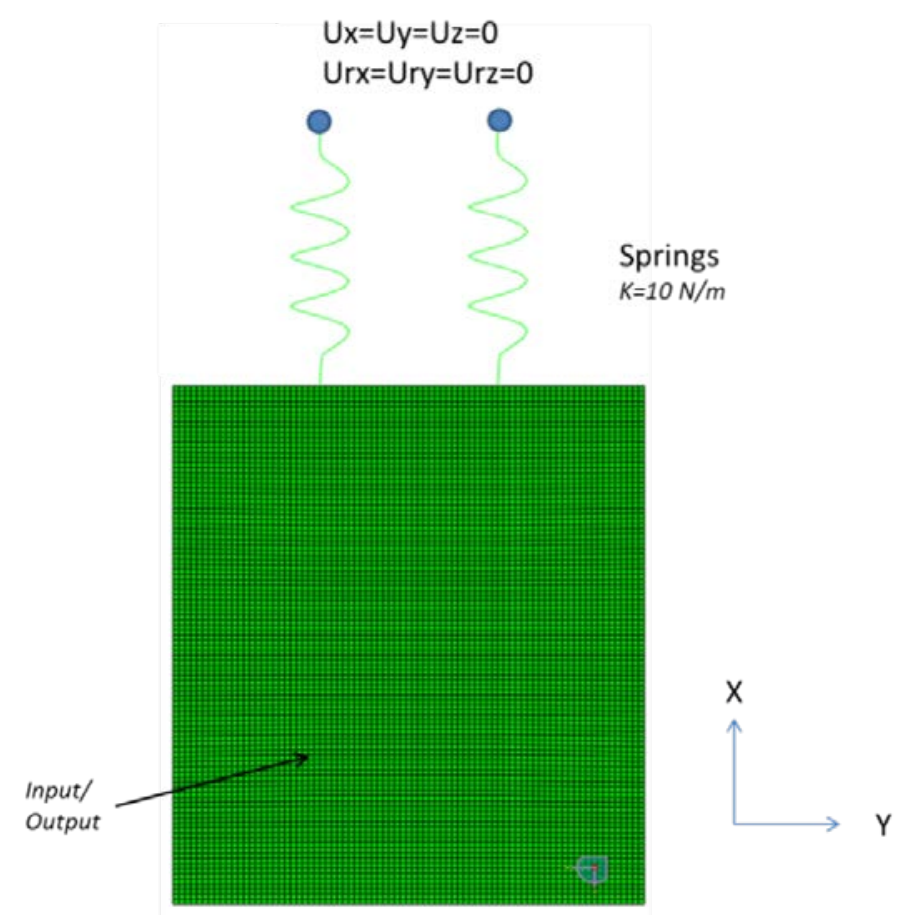

Figure 2: Finite element model 
The damping coefficients were extracted experimentally from all plates, using the Peak Picking method [13]. Table 3 shows the mean and the standard deviation of the damping ratios in terms of modes.

Table 3: Damping ratios for the six first mode shapes

\begin{tabular}{ccc}
\hline \multicolumn{3}{c}{$[\mathbf{0 / 1 5 / - 1 5 / 0 / 1 5 / - 1 5 ] s}$} \\
\hline \multirow{2}{*}{ Mode } & \multicolumn{2}{c}{ Damping Ratios } \\
& Mean & Std. dev. \\
\hline 1 & $0.63 \%$ & $0.09 \%$ \\
2 & $0.58 \%$ & $0.03 \%$ \\
3 & $0.57 \%$ & $0.06 \%$ \\
4 & $0.66 \%$ & $0.12 \%$ \\
5 & $1.08 \%$ & $0.25 \%$ \\
6 & $0.44 \%$ & $0.03 \%$ \\
\hline
\end{tabular}

\section{KRIGING BASED MODEL UPDATE}

A typical model update process consists of an optimization algorithm aiming to reduce the difference of the model results from the experimental results. Thus, the updated model is to obtain the design variables by using a FEM model, which returns the natural frequencies of the plates that better reproduce the experimental data. Therefore, a Particle Swarm Optimization (PSO) algorithm is used to search the most appropriate design variable values for each case. The strategy using the metamodel Kriging can significantly reduce the computational time of this process [12]. The model update is used to obtain the design variables that can result in the natural frequencies for the boundaries found in the experimental data. Table 4, shows the results obtained for plates [0/15/$15 / 0 / 15 /-15]_{s}$, considering the case of standard deviation.

Table 4: Maximum and minimum frequencies for plates [0/15/-15/0/15/-15] s considering standard deviation

\begin{tabular}{|c|c|c|c|c|c|c|}
\hline \multicolumn{7}{|c|}{ Boundaries for standard deviation } \\
\hline & $f 1[\mathrm{~Hz}]$ & $f 2[\mathrm{~Hz}]$ & $\begin{array}{l}f 3[\mathrm{~Hz}] \\
\text { Maxim }\end{array}$ & $f 4[\mathrm{~Hz}]$ & $f 5[\mathrm{~Hz}]$ & $f 6[\mathrm{~Hz}]$ \\
\hline Experimental & 107.39 & 145.65 & 267.42 & 333.62 & 380.40 & 426.84 \\
\hline Kriging & 108.56 & 146.77 & 264.59 & 333.62 & 380.40 & 423.67 \\
\hline Difference & $1.09 \%$ & $0.77 \%$ & $-1.06 \%$ & $0.00 \%$ & $0.00 \%$ & $-0.74 \%$ \\
\hline \multicolumn{7}{|c|}{ Minimum } \\
\hline Experimental & 103.17 & 138.74 & 259.01 & 319.70 & 364.53 & 410.76 \\
\hline Kriging & 103.17 & 140.01 & 251.91 & 319.70 & 364.55 & 404.44 \\
\hline Difference & $0.00 \%$ & $0.92 \%$ & $-2.74 \%$ & $0.00 \%$ & $0.00 \%$ & $-1.54 \%$ \\
\hline
\end{tabular}

The design variables resulted from this model update process are presented in Table 5. 
$4^{\text {th }}$ Brazilian Conference on Composite Materials. Rio de Janeiro, July $22^{\text {nd }}-25^{\text {th }}, 2018$

Table 5: Updated design variables

\begin{tabular}{lcccc}
\hline \multicolumn{5}{c}{ Boundaries for standard deviation } \\
& $E_{11}[\mathrm{GPa}]$ & $E_{22}[\mathrm{GPa}]$ & $G_{12}[\mathrm{GPa}]$ & $t[\mathrm{~mm}]$ \\
\hline Minimum & 137.72 & 10.13 & 4.73 & 3.24 \\
Maximum & 135.92 & 10.03 & 4.79 & 3.41 \\
\hline
\end{tabular}

Figure 3 shows the convergence of the PSO for the two cases previously studied.

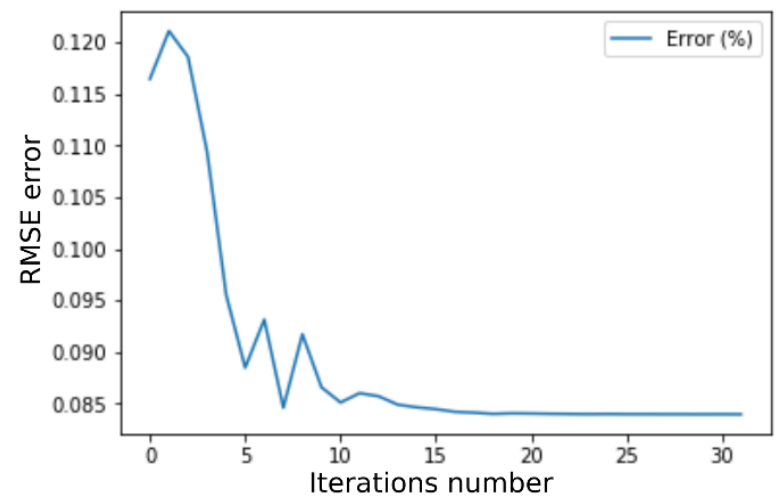

(a)

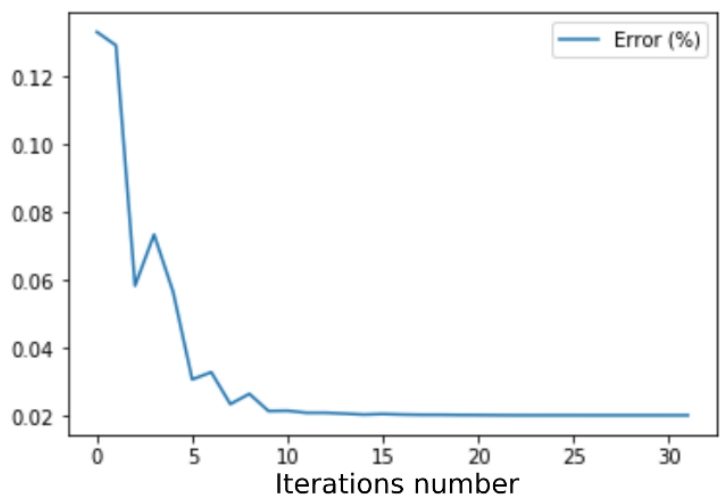

(b)

Figure 3: PSO convergence (a) maximum, (b) minimum

\section{FRF ANALYSES}

The FRFs show the global dynamic response of the system, and they are very useful on dynamic analysis. From the design variables determined via Kriging model update, it is possible to use a numerical model via FEM to obtain the correspondent FRF. Using the maximum and minimum values, the range of FRFs is created, and it can be compared to the experimental data of the plates in order to evaluate the admissibility of a project. Figure 4 shows the FRF for the minimum and maximum limits obtained.

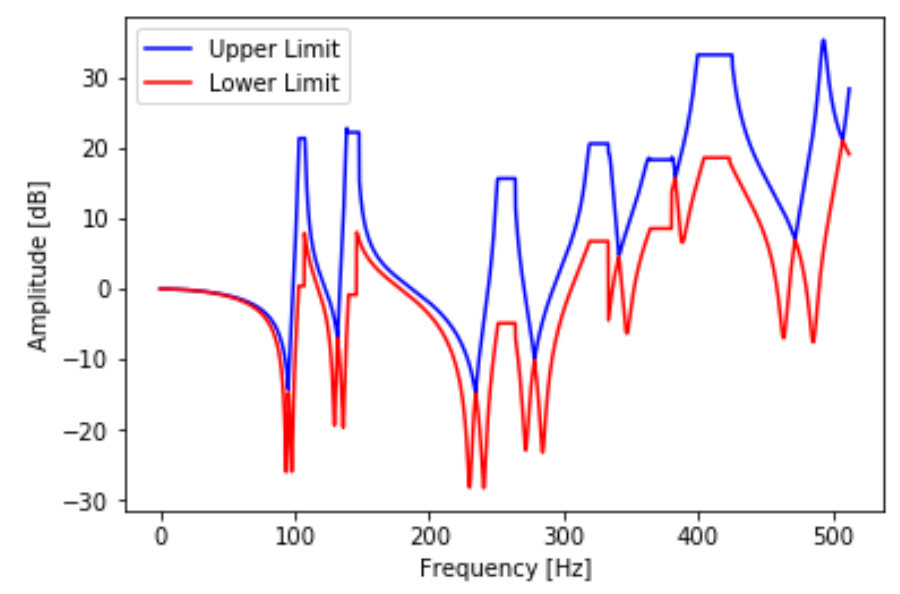

Figure 4: FRF obtained on FEM using the updated design variables 
Figure 5 presents the FRF limits and the experimental FRF of Plate 09 and Plate 10. It is possible to see that Plate 09 has a higher deviation than Plate 10. Calculating the percentage of the points in the limits, it is possible to note that Plate 09 has $33.28 \%$ of its points inner the limits, and Plate 10 has $48.16 \%$. Despite this, looking only for the positive part of the FRFs, it is possible to note that $48.10 \%$ of the FRF from Plate 09 is in the limits, whereas Plate 10 has $74.2 \%$ of its points within the limits. In addition, looking to the graphic Plate 09 is always on the left of the boundary limits, meaning that this component has a lower stiffness. This could be resulted by some problem on the manufacturing process as a lower thickness, high concentration of resin or even cracks and delaminations.

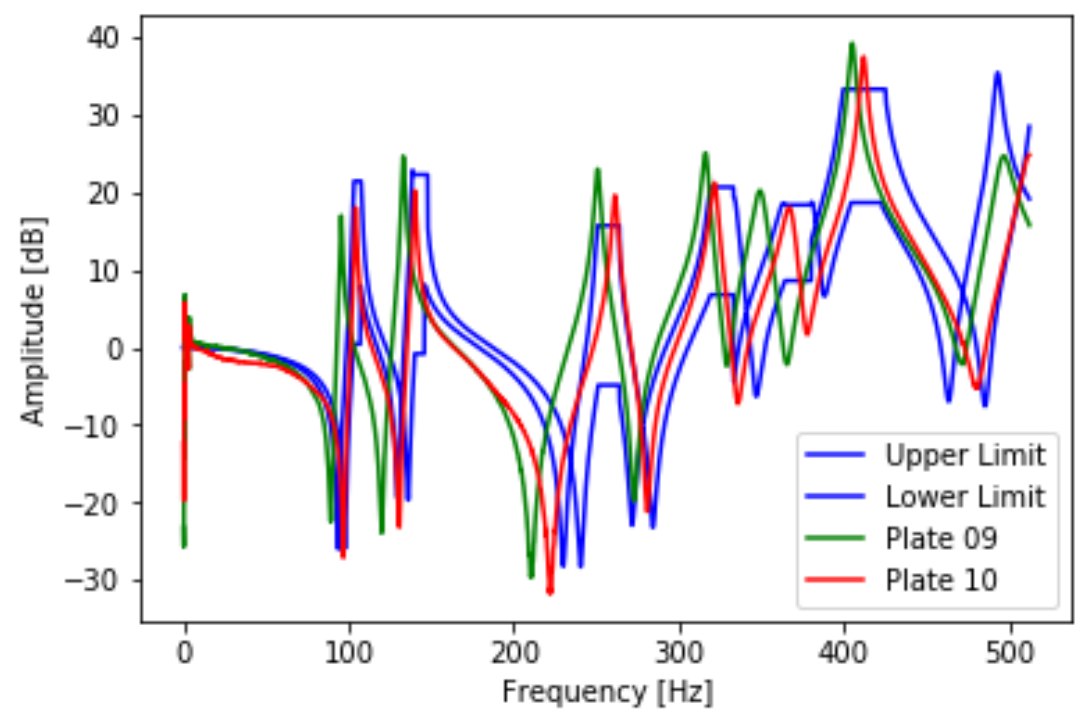

Figure 5: FRF limits and experimental FRF from Plate 09 and Plate 10

Therefore, Plate 09 should be not considered admissible to use as an intact plate in a monitoring system. It means that considering the tolerance of standard deviation from the analyzed set of plates, this plate does not match with the requirements, and should be verified about some manufacture imperfection.

\section{CONCLUSIONS}

This paper assesses the dynamic behavior of composite plates aiming to better identify the conditions after manufacturing. The experimental analysis shows clearly the variability on dynamic behavior for components manufactured with the same conditions, once the standard deviation for the natural frequency is about 4 to $8 \mathrm{~Hz}$. A model update process using Kriging Metamodel was used to obtain the extreme values of the dynamic behavior. This metamodel allows a reduction of the computational time during the model update, approximately from 1 hour to 10 minutes when compared with a pure Finite Element Analysis-based model update (desktop computer, memory: 4Gb, processor: Intel i5). The envelope generated on the case presented shows the identification of the admissible components that have more than $70 \%$ of its FRF inner the envelope. Therefore, these results show that it is possible to identify components with the required specifications in terms of dynamic behavior. 
$4^{\text {th }}$ Brazilian Conference on Composite Materials. Rio de Janeiro, July $22^{\text {nd }}-25^{\text {th }}, 2018$

\section{ACKNOWLEDGMENTS}

The authors acknowledge the financial support of the State Research Founding Agency (FAPESC process number: 2017TR1747 and 2017TR784). As well as, Sao Paulo State Research Foundation (FAPESP process number: 2012/01047-8 and 2015/15221-8), Coordination for the Improvement of the Higher Level Personnel (CAPES process number: 011214/2013-09), National Council for Scientific and Technological Development (CNPq process number: 401170/2014-4 and 310094/2015-1). The authors also would like to thank Navy Technological Centre (CTM Brazil) for manufacturing specimens and Prof. Joel Martins Crichigno Filho (Santa Catarina State University - Brazil) for kindly providing the use of the ABAQUS ${ }^{\mathrm{TM}}$ license.

\section{REFERENCES}

[1] Alaswad, S., \& Xiang, Y. (2017). A review on condition-based maintenance optimization models for stochastically deteriorating system. Reliability Engineering \& System Safety, 157, 54-63.

[2] Rastegari, A., Archenti, A., \& Mobin, M. (2017, January). Condition based maintenance of machine tools: Vibration monitoring of spindle units. In Reliability and Maintainability Symposium (RAMS), 2017 Annual (pp. 1-6). IEEE.

[3] Peeters, C., Guillaume, P., \& Helsen, J. (2018). Vibration-based bearing fault detection for operations and maintenance cost reduction in wind energy. Renewable Energy, 116, 74-87.

[4] De Medeiros R, Vandepitte D, Tita V. Structural health monitoring for impact damaged composite: a new methodology based on a combination of techniques. Structural Health Monitoring, v17, n.2, p.185-200, 2018.

[5] Sohn H, Farrar CR, Hemez FM, Czarnecki J. A review of structural health monitoring literature. Report, Los Alamos, NM: Los Alamos National Laboratory, 2003.

[6] Sinou J. A review of damage detection and health monitoring of mechanical systems from changes in the measurement of linear and non-linear vibrations, Robert C. Sapri. Mechanical Vibrations: Measurement, Effects and Control, Nova Science Publishers, Inc., pp.643-702, 2009, 978-1-60692037-4.

[7] Farrar CR, Doebling SW, Nix DA. Vibration based structural damage identification. Philosophical Transactions of the Royal Society A, 2001(359):131149.

[8] Montalvo D, Maia MMN, Ribeiro AMR. A review of vibration-based structural health monitoring with special emphasis on composite materials. Shock and Vibration, 2006(38):295-324.

[9] Kim JT, Ryu YS, Cho HM, Stubbs N. Damage identification in beam-type structures: frequencybased method vs mode-shape-based method. Engineering Structures, 2003(25):57-67.

[10]Kessler SS, Spearing SM, Atalla MJ, Cesnik CE, Soutis C. Damage detection in composite materials using frequency response methods. Composites Part B: Engineering, 2002(33):87-95.

[11]De Medeiros R, Lopez H, Guedes R, Vaz M, Vandepitte D, Tita V. A new approach for SHM system: Combination of vibration based method and shearography speckle. In: 5th International Symposium on Solid Mechanics (MecSol2015), Belo Horizonte, Brazil, 2015.

[12]Magalhães F, Cunha A, Caetano E. Vibration based structural health monitoring of an arch bridge: From automated OMA to damage detection. Mechanical Systems and Signal Processing, 2012(28):212-228.

[13]Souza L F S, Tita V, De Medeiros R. Composite Plates Model Update using Kriging Method. In: 24th ABCM International Congress of Mechanical Engineering (COBEM2017), Curitiba, Brazil, 2017. 